\title{
EDITORIAL
}

\section{COVID-19-related and non-COVID-related acute respiratory distress syndrome: two sides of the same coin?}

\author{
Audrey de Jong ${ }^{1,2}$, Oriol Roca ${ }^{3,4,5}$ and Claude Guérin ${ }^{6,7,8^{*}}$ (B)
}

(c) 2020 Springer-Verlag GmbH Germany, part of Springer Nature

In the setting of the coronavirus disease 2019 (COVID19) pandemic that has hit ICUs worldwide Ferrando et al. [1] recently published a prospective multicentre study conducted in 36 Spanish ICUs. The study focused on consecutive patients with COVID-19-related acute respiratory distress syndrome (COVID ARDS) who required invasive mechanical ventilation. Among the wealth of important and carefully recorded information provided by this study, the present editorial focuses on anticipated differences between COVID ARDS and non-COVID19-related ARDS (non-COVID ARDS), on tidal volume setting, adjunct therapies and on methodological aspects.

The first, and main, controversy concerns the idea that "COVID-19 does not lead to a typical ARDS", a hypothesis supported by the observation of 16 patients who were severely hypoxaemic but had relatively preserved respiratory system compliance (Crs) together with good lung aeration on CT scan [2]. On the basis of these findings the authors proposed avoiding high levels of positive end-expiratory pressure (PEEP) and suggested that proning may be associated with limited benefits that, in the context of the pandemic, must be balanced with the high cost of human resources. In another editorial [3], the same authors described the existence of two different phenotypes based on: elastance levels $(1 / \mathrm{Crs})$, pulmonary ventilation-to-perfusion ratio, lung weight, and lung recruitability. These two phenotypes, named types $\mathrm{L}$ and $\mathrm{H}$, are characterised by low and high levels of all these variables, respectively. It has been proposed that

*Correspondence: claude.guerin@chu-lyon.fr

${ }^{6}$ Medecine Intensive-Réanimation, Groupement Hospitalier Lyon Centre, Hôpital Edouard-Herriot, 5 Place d'Arsonval, 69003 Lyon, France

Full author information is available at the end of the article patients with COVID-19 present early with the type L phenotype, and that some of them evolve to the type $\mathrm{H}$ phenotype due to COVID-19 progression and a mechanism reported to lead to patient self-inflicted lung injury [4]. Calfee et al. [5] have previously sought to phenotype non-COVID ARDS. Using the latent class analysis method, they identified a hyper-inflammatory phenotype and a low-inflammatory phenotype characterised by different responses to PEEP. The results of several studies of COVID ARDS have suggested that the respiratory mechanics and lung recruitability in these patients may be similar to those observed in non-COVID ARDS patients. In their large multicentre study, Ferrando et al. [1] attempted to corroborate this hypothesis by comparing their results with the averaged results of previous studies. No differences were observed in Crs, plateau pressure, or driving pressure.

Roughly $75 \%$ of their patients received a tidal volume $\left(V_{\mathrm{T}}\right)$ greater than $6 \mathrm{ml} / \mathrm{kg}$ predicted body weight $(\mathrm{PBW})$, with $25 \%$ of them receiving a $V_{\mathrm{T}}$ greater than $9.5 \mathrm{ml} / \mathrm{kg}$ PBW. Furthermore, confirming the findings of the LUNG SAFE study in non-COVID ARDS [6], $V_{\mathrm{T}}$ was similar across ARDS severity categories. An important part of the paper concerned the comparison between patients with a normal $\left(\geq 50 \mathrm{ml} / \mathrm{cmH}_{2} \mathrm{O}\right)$ versus low $(<50 \mathrm{ml} /$ $\mathrm{cmH}_{2} \mathrm{O}$ ) Crs [3]. Remarkably, $V_{\mathrm{T}}$ was not found to differ between the two groups, and the same applied to the other ventilator settings including PEEP. The first question that arises is why measure Crs? The finding that $\mathrm{Crs}$ reflects the amount of aerated lung [7] previously led to the baby lung concept. According to this concept, the greater the amount of aerated (open) lung the higher the $V_{\mathrm{T}}$ should be, at a given PEEP. A secondary analysis of the ARMA trial [8] found that raising $V_{\mathrm{T}}$ decreased

\section{Springer}


mortality in patients with higher pre-randomisation Crs, but increased mortality in those with lower prerandomisation Crs [9]. However, a subsequent increase in $V_{\mathrm{T}}$ was found to increase (by $15 \%$ per $1 \mathrm{ml} / \mathrm{kg} \mathrm{PBW}$ $V_{\mathrm{T}}$ increase) the risk of death in a prospective cohort of non-COVID ARDS patients [10]. Crs was not taken into account in that cohort study. Therefore, it is not clear how those clinicians set $V_{\mathrm{T}}$ and whether they would adopt a Crs strategy for that, as they seem keener to follow a strategy based on driving pressure to adjust $V_{\mathrm{T}}$ and PEEP. Second, lung compliance may be more useful than Crs to characterise patients according to obesity difference between the two Crs groups. Crs and lung compliance can be expressed as percentage of predicted values [11]. The rate of use of adjunct therapies was also similar between the two Crs groups. Use of inhaled nitric oxide was not mentioned, whereas a role of lung microcirculation in COVID ARDS was suggested. A large majority of patients received recruitment manoeuvers irrespective of ARDS severity and without assessment of the underlying recruitability. Prone position was largely used in both groups, e.g. at a more than twice the rate found in a previous study [12]. This result strongly suggests that clinicians have now adopted the prone position strategy.
It should be mentioned that the procedure was used in more than $60 \%$ of mild COVID ARDS patients, even though use of the prone postion in mild ARDS is not evidence-based.

Regarding the statistical analysis and methodology employed, the study of Ferrando et al. [1] has several strengths and limitations. The large sample size and the multicentre design allow the results to be extrapolated to other ICUs in Spain and worldwide. The observational "real-life" design prevents selection and information biases [13]. However, the flow chart does not give the total number of patients admitted to the ICUs during the study period. Similarly, the nature of missing data (completely missing or partly missing, at random or not at random) [14] was not assessed. Some important respiratory variables such as mechanical power $[15,16]$ were not reported. A further limitation is the lack of a control group with non-COVID ARDS in the same cohort of patients during the same period. The comparison was not done with non COVID-19 cohorts gathered in the same time as the present COVID-19 cohort. Moreover, in lacking an a priori specified hypothesis and pre-defined sample size, the study fails to comply with the STROBE statement for reporting observational studies [17]. It

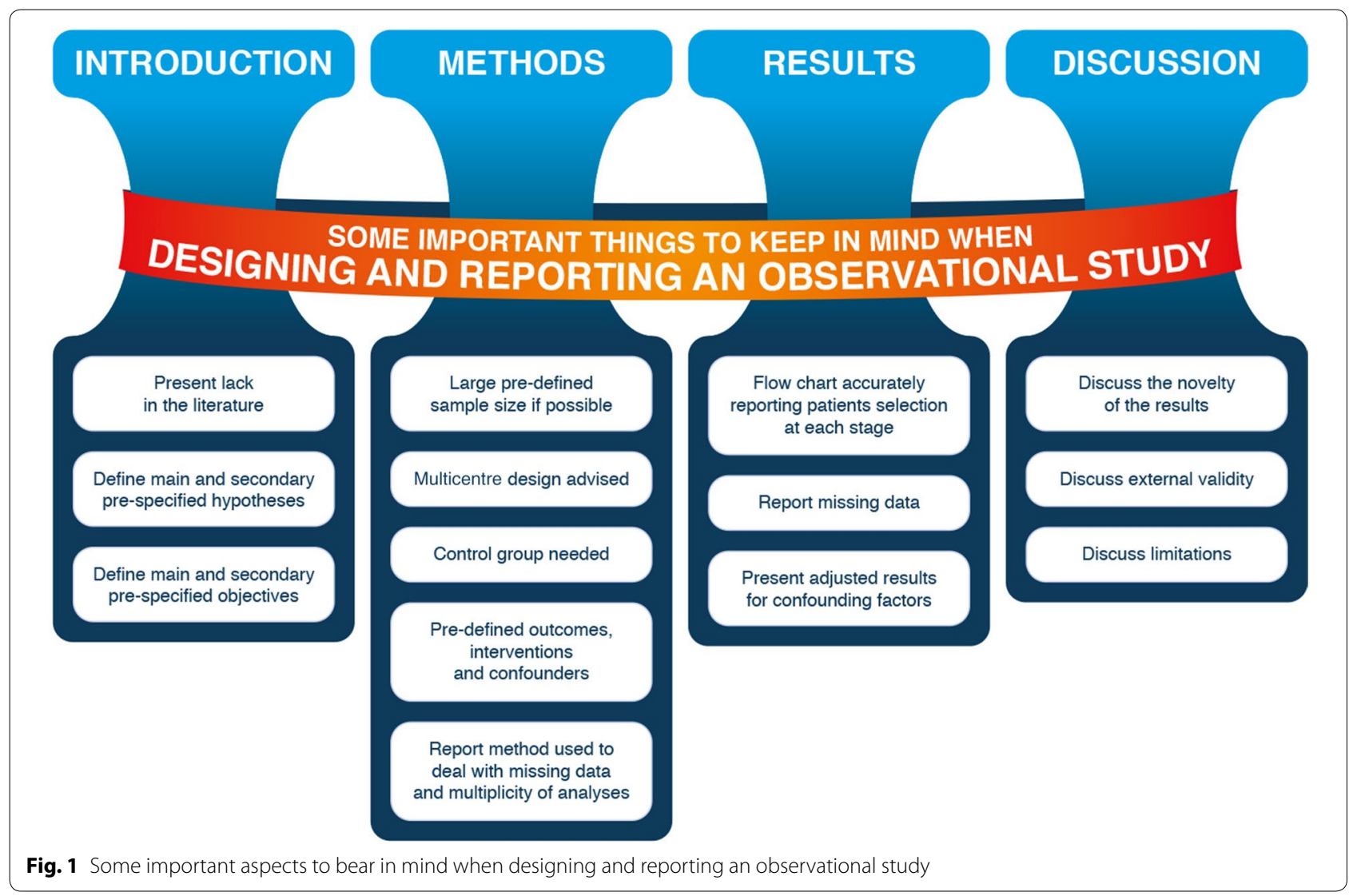


is therefore possible that readers may misinterpret the lack of statistically significant differences between mild, moderate and severe ARDS patients, low and normal Crs patients, or COVID and non-COVID ARDS patients, particularly as evaluation of such differences was not the main objective of the study. Furthermore, because of the low grade of imbalance between groups in the relevant baseline variables, the statistical analysis was not adjusted for confounding factors. An adjustment performed according to predefined variables, available in the literature, would have strengthened the results presented. Figure 1 highlights some important aspects to bear in mind when designing and reporting an observational study.

Given all these limitations and considering the inherent heterogeneity of ARDS, it could be that, at the time of intubation, COVID ARDS is not different from ARDS of other causes. The results presented by Ferrando et al. must be considered descriptive and exploratory, and no firm conclusion can be drawn from them without additional data. However, it can be stated that after careful bedside physiological assessment, COVID ARDS patients may be managed according to the evidence-based recommendations.

\begin{abstract}
Author details
${ }^{1}$ Anesthesiology and Intensive Care; Anesthesia and Critical Care Department B, Saint Eloi Teaching Hospital, PhyMedExp, INSERM U1046, CNRS, UMR 9214, University of Montpellier, 34295 Montpellier Cedex 5, France. ${ }^{2}$ Centre Hospitalier Universitaire Montpellier, 34295 Montpellier, France. ${ }^{3}$ Servei de Medicina Intensiva, Hospital Universitari Vall d'Hebron, Institut de Recerca Vall d'Hebron, Barcelona, Spain. ${ }^{4}$ Departament de Medicina, Universitat Autònoma de BarceIona, Bellaterra, Spain. ${ }^{5}$ Ciber Enfermedades Respiratorias (Ciberes), Instituto de Salud Carlos III, Madrid, Spain. ${ }^{6}$ Medecine Intensive-Réanimation, Groupement Hospitalier Lyon Centre, Hôpital Edouard-Herriot, 5 Place d'Arsonval, 69003 Lyon, France. ${ }^{7}$ Université de Lyon, Lyon, France. ${ }^{8}$ Institut Mondor de Recherches Biomédicales, INSERM 955, Créteil, France.
\end{abstract}

\section{Compliance with ethical standards}

\section{Conflicts of interest}

The authors declare that they have no conflict of interest.

\section{Publisher's Note}

Springer Nature remains neutral with regard to jurisdictional claims in published maps and institutional affiliations.

Received: 12 August 2020 Accepted: 26 August 2020

Published online: 2 October 2020

\section{References}

1. Ferrando C, Suarez-Sipmann F, Mellado-Artigas R, Hernandez M, Gea A, Arruti E, Aldecoa C, Martinez-Palli G, Martinez-Gonzalez MA, Slutsky AS, Villar J, COVID-19 Spanish ICU Network (2020) Clinical features, ventilatory management, and outcome of ARDS caused by COVID-19 are similar to other causes of ARDS. Intensive Care Med. https://doi.org/10.1007/s0013 4-020-06192-2

2. Gattinoni L, Coppola S, Cressoni M, Busana M, Rossi S, Chiumello D (2020) COVID-19 does not lead to a "typical" acute respiratory distress syndrome. Am J Respir Crit Care Med 201:1299-1300

3. Gattinoni L, Chiumello D, Caironi P, Busana M, Romitti F, Brazzi L, Camporota L (2020) COVID-19 pneumonia: different respiratory treatments for different phenotypes? Intensive Care Med 46:1099-1102

4. Brochard L, Slutsky A, Pesenti A (2017) Mechanical ventilation to minimize progression of lung injury in acute respiratory failure. Am J Respir Crit Care Med 195:438-442

5. Calfee CS, Delucchi K, Parsons PE, Thompson BT, Ware LB, Matthay MA (2014) Subphenotypes in acute respiratory distress syndrome: latent class analysis of data from two randomised controlled trials. Lancet Respir Med 2:611-620

6. Bellani G, Laffey JG, Pham T, Fan E, Brochard L, Esteban A, Gattinoni L, van Haren F, Larsson A, McAuley DF, Ranieri M, Rubenfeld G, Thompson BT, Wrigge H, Slutsky AS, Pesenti A, Investigators LS, Group ET (2016) Epidemiology, patterns of care, and mortality for patients with acute respiratory distress syndrome in intensive care units in 50 countries. JAMA $315: 788-800$

7. Gattinoni L, Pesenti A, Avalli L, Rossi F, Bombino M (1987) Pressurevolume curve of total respiratory system in acute respiratory failure. Computed tomographic scan study. Am Rev Respir Dis 136:730-736

8. Brower RG, Matthay MA, Morris A, Schoenfeld D, Thompson BT, Wheeler A (2000) Ventilation with lower tidal volumes as compared with traditional tidal volumes for acute lung injury and the acute respiratory distress syndrome. N Engl J Med 342:1301-1308

9. Deans KJ, Minneci PC, Cui X, Banks SM, Natanson C, Eichacker PQ (2005) Mechanical ventilation in ARDS: one size does not fit all. Crit Care Med 33:1141-1143

10. Needham DM, Yang T, Dinglas VD, Mendez-Tellez PA, Shanholtz C, Sevransky JE, Brower RG, Pronovost PJ, Colantuoni E (2015) Timing of low tidal volume ventilation and intensive care unit mortality in acute respiratory distress syndrome. A prospective cohort study. Am J Respir Crit Care Med 191:177-185

11. Guérin C, Terzi N, Galerneau LM, Mezidi M, Yonis H, Baboi L, Kreitmann L, Turbil E, Cour M, Argaud L, Louis B (2020) Lung and chest wall mechanics in patients with acute respiratory distress syndrome, expiratory flow limitation, and airway closure. J Appl Physiol (1985) 128:1594-1603

12. Guérin $C$, Beuret $P$, Constantin JM, Bellani G, Garcia-Olivares P, Roca $\mathrm{O}$, Meertens JH, Maia PA, Becher T, Peterson J, Larsson A, Gurjar M, Hajjej Z, Kovari F, Assiri AH, Mainas E, Hasan MS, Morocho-Tutillo DR, Baboi L, Chrétien JM, François G, Ayzac L, Chen L, Brochard L, Mercat A (2018) A prospective international observational prevalence study on prone positioning of ARDS patients: the APRONET (ARDS Prone Position Network) study. Intensive Care Med 44:22-37

13. Helms J, Bion J, De Jong A (2019) Observational vs randomized: David vs Goliath for thromboprophylaxis in critically ill patients? Intensive Care Med 45:272-274

14. Madley-Dowd P, Hughes R, Tilling K, Heron J (2019) The proportion of missing data should not be used to guide decisions on multiple imputation. J Clin Epidemiol 110:63-73

15. Tonna JE, Peltan I, Brown SM, Herrick JS, Keenan HT (2020) Mechanical power and driving pressure as predictors of mortality among patients with ARDS. Intensive Care Med. https://doi.org/10.1007/s00134-02006130-2

16. Serpa Neto A, Deliberato RO, Johnson AE, Pollard TJ, Celi LA, Pelosi P, Gama de Abreu M, Schultz MJ (2019) Normalization of mechanical power to anthropometric indices: impact on its association with mortality in critically ill patients. Intensive Care Med 45:1835-1837

17. Wang X, Kattan MW (2020) Cohort studies: design, analysis, and reporting. Chest 158:S72-S78 